\title{
The management of functional dyspepsia in clinical practice: what lessons can be learnt from recent literature? [version 1; peer review: 2 approved]
}

\author{
Maura Corsetti(D)1, Mark Fox²,3
}

\begin{abstract}
${ }^{1}$ National Institute for Health Research, Nottingham Digestive Diseases Biomedical Research Centre, Nottingham University Hospitals NHS Trust, University of Nottingham, Nottingham, UK

${ }^{2}$ Abdominal Centre: Gastroenterology, St Claraspital, Basel, Switzerland

${ }^{3}$ Clinic of Gastroenterology \& Hepatology, University Hospital Zürich, Zürich, Switzerland
\end{abstract}

V1 First published: 28 Sep 2017, 6(F1000 Faculty Rev):1778

https://doi.org/10.12688/f1000research.12089.1

Latest published: 28 Sep 2017, 6(F1000 Faculty Rev):1778

https://doi.org/10.12688/f1000research.12089.1

\section{Open Peer Review}

Approval Status

1

2

version 1

28 Sep 2017

Faculty Reviews are review articles written by the prestigious Members of Faculty Opinions. The articles are commissioned and peer reviewed before publication to ensure that the final, published version is comprehensive and accessible. The reviewers who approved the final version are listed with their names and affiliations.

1. Fermin Mearin, Centro Médico Teknon,

Barcelona, Spain

2. Hiroto Miwa, Hyogo College of Medicine, Nishinomiya, Hyogo, Japan

Any comments on the article can be found at the end of the article. 
Corresponding author: Maura Corsetti (maura.corsetti@nottingham.ac.uk)

Author roles: Corsetti M: Conceptualization, Data Curation, Resources, Writing - Original Draft Preparation, Writing - Review \& Editing; Fox M: Resources, Writing - Original Draft Preparation, Writing - Review \& Editing

Competing interests: The author declares that he has no competing interests.

Grant information: The author(s) declared that no grants were involved in supporting this work.

Copyright: $\odot 2017$ Corsetti $\mathrm{M}$ and Fox $\mathrm{M}$. This is an open access article distributed under the terms of the Creative Commons Attribution License, which permits unrestricted use, distribution, and reproduction in any medium, provided the original work is properly cited.

How to cite this article: Corsetti $\mathrm{M}$ and Fox $\mathrm{M}$. The management of functional dyspepsia in clinical practice: what lessons can be learnt from recent literature? [version 1; peer review: 2 approved] F1000Research 2017, 6(F1000 Faculty Rev):1778

https://doi.org/10.12688/f1000research.12089.1

First published: 28 Sep 2017, 6(F1000 Faculty Rev):1778 https://doi.org/10.12688/f1000research.12089.1 


\section{Introduction}

About $20 \%$ of the population has chronic symptoms that can be attributed to disorders of gastroduodenal motility and function, which the recently published Rome IV criteria have classified into four categories: functional dyspepsia (FD), belching disorders, chronic nausea and vomiting disorders, and rumination syndrome $^{1}$. This diagnostic classification is largely unchanged from previous iterations with only minor changes made to the definition (Table 1).

\section{Definition}

FD is a functional gastrointestinal (GI) disorder characterized by one or more of the following symptoms: postprandial fullness, early satiation, epigastric pain, and epigastric burning ${ }^{1}$. Nausea and vomiting are no longer considered cardinal FD symptoms and have been moved into separate categories of functional nausea and vomiting disorders ${ }^{2}$. Based on factor analyses of digestive symptoms in the general population and FD patients, the Rome Committee further divided patients with FD into two subgroups: postprandial distress syndrome (PDS), which is characterized by meal-induced symptoms, and epigastric pain syndrome (EPS), which refers to epigastric pain or epigastric burning that does not occur exclusively postprandially and can even be improved by meal ingestion ${ }^{2}$. In clinical practice, PDS is more prevalent than EPS ${ }^{1}$; however, the overlap between PDS and EPS patients has been reported to be as high as $50 \%{ }^{1,2}$. Therefore, the clinical utility of this subdivision has been questioned ${ }^{1}$, even though it seems reasonable to distinguish between patients with symptoms induced by food intake (that is, PDS, previously called "dysmotility-like") and those in whom symptoms are largely independent of GI function (that is, EPS, previously called "ulcer-like"). Moreover, a recent study has demonstrated that the overlap can be reduced by a more rigorous linking of postprandially occurring symptoms to PDS, regardless of their qualitative nature ${ }^{3,4}$. This means that epigastric pain or burning, if postprandial, can also be present in $\operatorname{PDS}^{3,4}$. One change made by Rome IV is to limit the diagnosis of FD to patients with "bothersome symptoms... severe enough to impact on usual activities" occurring with a minimal frequency of 3 days per week ${ }^{1}$. This is necessary to distinguish those with clinically relevant disease from healthy subjects with occasional, relatively mild symptoms that can be considered part of normal daily life. FD patients who meet these diagnostic criteria have reduced quality of life and incur significant direct costs through medical expenses and indirectly through loss of productivity ${ }^{1}$.

\section{Pathophysiology}

The causes of FD are not completely understood; however, several mechanisms appear to be involved. These include altered gastric emptying, impaired gastric accommodation, gastric and duodenal hypersensitivity, and previous GI infections ${ }^{1}$. Additionally, the presence of psychiatric disease and psychosocial stress factors has a role in FD aetiology and severity ${ }^{1}$. Delayed gastric emptying has been reported in up to $35 \%$ of patients with FD, whereas rapid gastric emptying, even if less studied, is probably

Table 1. Rome IV criteria for functional dyspepsia.

Diagnostic Rome IV criteria for functional dyspepsia (changes from Rome III criteria appear in bold)

1. One or more of the following: a. bothersome postprandial fullness; b. bothersome early satiation; c. bothersome epigastric pain; d. bothersome epigastric burning AND 2. No evidence of structural disease (including at upper endoscopy) that is likely to explain the symptoms

${ }^{*}$ Criteria fulfilled for the last 3 months with symptom onset at least 6 months before diagnosis

Diagnostic criteria for postprandial distress syndrome

Must include one or both of the following at least 3 days per week:

1. Bothersome postprandial fullness (that is, severe enough to impact on usual activities)

2. Bothersome early satiation (that is, severe enough to prevent finishing a regular-sized meal)

Supportive criteria

1. Postprandial epigastric pain or burning, epigastric bloating, excessive belching, and nausea can also be present; 2 . vomiting warrants consideration of another disorder; 3 . heartburn is not a dyspeptic symptom but may often co-exist; 4 . symptoms that are relieved by evacuation of faeces or gas should generally not be considered part of dyspepsia; 5 . other individual digestive symptoms or groups of symptoms (such as from gastro-oesophageal reflux disease and irritable bowel syndrome) may co-exist with postprandial distress syndrome.

Diagnostic criteria for epigastric pain syndrome

Must include at least one of the following symptoms at least 1 day a week:

1. Bothersome epigastric pain (that is, severe enough to impact on usual activities)

2. Bothersome epigastric burning (that is, severe enough to impact on usual activities)

Supportive criteria

1. Pain may be induced by ingestion of a meal, may be relieved by ingestion of a meal, or may occur while fasting; 2 . postprandial epigastric bloating, belching, and nausea can also be present; 3. persistent vomiting likely suggests another disorder;

4. heartburn is not a dyspeptic symptom but may often co-exist; 5 . the pain does not fulfil biliary pain criteria; 6 . symptoms that are relieved by evacuation of faeces or gas generally should not be considered part of dyspepsia; 7 . other digestive symptoms (such as from gastro-oesophageal reflux disease and irritable bowel syndrome) may co-exist with epigastric pain syndrome. 
present in a lower percentage of patients ${ }^{1}$. Impaired gastric relaxation in response to food (that is, impaired accommodation) has also been found in about one third of patients with FD ${ }^{1}$. Hypersensitivity to mechanical stimulation (for example, distention) of the stomach or the small bowel (or both) is frequent, and affected patients may also show hypersensitivity to chemical stimuli such as acid and lipids ${ }^{1}$. Acute infection is known to trigger so-called "post-infectious FD" in at least $10-20 \%$ of individuals". The diagnosis of "Helicobacter pylori-associated dyspepsia" can be made if successful eradication leads to long-term resolution of symptoms ${ }^{1}$. A relationship between the gut and psyche has been described in this condition because patients with psychological disease (that is, anxiety or depression) are at increased risk of developing FD, and vice versa ${ }^{1}$. Many of these factors can impact on mucosal integrity and duodenal permeability, effects that have been related to the activation of the innate mucosal immune system. Experimental evidence provides some insight into this complex mechanism in humans. Psychological stress mediated by corticotrophin-releasing hormone has been shown to alter intestinal permeability through a mast cell-dependent mechanism ${ }^{5}$. Recent research has also shown differences in the duodenal microbiome between patients with FD and controls, although it remains uncertain whether this represents "cause or effect".

Studies have also evaluated whether the two FD subgroupsPDS and EPS - differ with regard to pathophysiological mechanisms. The results suggest that PDS is associated with gastric hypersensitivity, delayed gastric emptying, anxiety, and the presence of increased intra-epithelial eosinophils in the duodenum and other evidence of an activated mucosal immune system ${ }^{6-9}$. Additionally, PDS presents frequently "as an overlap syndrome" with other functional GI disorders (for example, irritable bowel syndrome, or IBS $)^{10}$. In contrast, patients with EPS have little evidence of abnormal GI motility and function. EPS may be associated with the presence of other centrally mediated pain syndromes (for example, fibromyalgia) ${ }^{11}$.

\section{Diagnosis}

The diagnosis of FD is based on clinical assessment and exclusion of organic disease. Thus, before the diagnosis of FD is made, laboratory tests and upper GI endoscopy with biopsies are normally performed to exclude infection (in particular, H. pylori), peptic ulceration, celiac disease, and neoplasia ${ }^{1}$. Physiological investigations are normally not required at this stage ${ }^{1}$.

\section{Differential diagnosis}

Gastro-oesophageal reflux disease (GERD) is a potential cause of "dyspeptic symptoms" that is highly prevalent in the community. GERD is present when the reflux of stomach contents causes symptoms or mucosal disease (or both) and is characterized by the presence of heartburn and regurgitation. Formally, if heartburn is present, then this excludes the diagnosis of FD in the Rome IV classification $^{12}$. However, studies show that reflux and dyspeptic symptoms co-exist in up to $40 \%$ of cases, which is much more often than expected by chance ${ }^{13-15}$. This overlap between GERD and FD is not surprising given the immediate proximity and shared innervation of the oesophagus and proximal stomach.
Rome IV divides patients with GERD into those with erosive reflux disease (ERD), non-ERD (NERD, pathological acid exposure), reflux hypersensitivity (RH, normal acid exposure but association between reflux and symptoms), and functional heartburn ( $\mathrm{FH}$, no association between reflux and symptoms) $)^{12}$. FD overlaps with ERD, NERD, RH, and FH with increasing frequency. Patients with FH have more frequent PDS symptoms, whereas patients with NERD have more EPS symptoms (typically, epigastric burning $)^{15,16}$. Conversely, pathological acid exposure is present in about one third of patients with a clinical diagnosis of FD and in at least half of the subgroup with epigastric burning, which also more frequently responds to proton pump inhibitor (PPI) therapy ${ }^{17}$. Not only oesophageal but also duodenal acid exposure has been linked to EPS. Acid exposure of the duodenum is also associated with duodenal infiltration with inflammatory cells in patients with $\mathrm{FD}^{18}$. Mucosal acid exposure is a possible mechanism in duodenal permeability, predisposing to duodenal inflammation and altered sensitivity ${ }^{19}$. These observations may well explain why a proportion of FD patients without GERD respond to acid suppression. It is clear that several pathologies can cause symptoms, and conversely it is very likely that the overlap between the two functional conditions is the result of the shared pathophysiological mechanisms (for example, hypersensitivity) playing a role in two different regions of the GI tract. If the diagnosis remains uncertain after a trial of acid suppression, then manometry and ambulatory $\mathrm{pH}$-impedance studies provide an objective assessment of oesophageal acid exposure and the association between reflux and patient symptoms ${ }^{12}$. Additionally, these tests can identify dysmotility (for example, oesophageal spasm) that can present with similar symptoms and behavioural conditions (for example, rumination syndrome) that are frequently triggered by dyspeptic symptoms ${ }^{12}$.

FD can also overlap with chronic nausea and vomiting disorders. According to Rome IV criteria, these disorders include chronic nausea and vomiting syndrome (CNVS), cyclic vomiting syndrome (CVS), and cannabinoid hyperemesis syndrome $(\mathrm{CHS})^{1}$. CNVS is characterized by the presence of bothersome (that is, severe enough to impact on usual activities) nausea, occurring at least 1 day per week and/or one or more vomiting episodes per week in the absence of an organic explanation of symptoms or of self-induced vomiting, eating disorders, regurgitation, or rumination. CVS is characterized by stereotypical episodes of vomiting regarding onset (acute) and duration (less than 1 week) with at least three discrete episodes in the prior year and two episodes in the past 6 months, occurring at least 1 week apart in the absence of vomiting between episodes. CHS is characterized by episodes resembling CVS in terms of onset, duration, and frequency; presents after prolonged excessive cannabis use; and is relieved by sustained cessation of cannabis use. These disorders have been, in general, poorly studied, and it is possible that they overlap with other functional disorders. Given the current knowledge about these disorders, it is necessary to identify patients with nausea or vomiting (or both) as prevalent symptoms, as these patients are more difficult to manage in clinical practice and probably should be referred to specialized centres. 
IBS is a frequent functional disorder with a prevalence of about $10 \%$ in the general population. Rome IV defines the condition in terms of the presence of chronic recurrence of pain in association with defaecation and/or an altered bowel habit in terms of either stool frequency or stool consistency ${ }^{20}$. An important overlap is present between FD and IBS with both occurring in $30 \%$ and $60 \%$ of patients, respectively ${ }^{10}$. Overlap may be more common in patients with severe symptoms than in patients with mild symptoms and in PDS than in EPS, especially in patients with postprandial fullness ${ }^{10,21,22}$. Moreover, longitudinal studies demonstrate that the risk of a patient with FD developing IBS is increased by up to eightfold compared with the general population $^{23}$. These findings have led many to question whether these conditions are truly distinct or share common pathogenic mechanisms. Indeed, the pathophysiological mechanisms shared by PDS and IBS are very similar and include anxiety, altered motility, and visceral hypersensitivity. Low-grade inflammation with activation of the innate mucosal immune system and increased mucosal permeability has also been documented in both conditions ${ }^{19}$.

\section{Management}

The management of patients with FD should start with reassurance and education about the possible pathophysiological and risk factors associated with FD appropriate for the PDS or EPS subgroup or both ${ }^{1}$. Lifestyle and dietary recommendations may be helpful ${ }^{1,24}$. Avoidance of non-steroidal anti-inflammatory drugs, coffee, high-fat foods, alcohol, and smoking is commonly recommended on the basis of physiological studies and case reports; however, the real value of these recommendations is unclear ${ }^{1,24}$.

The next step recommended by the Rome committee is to exclude iatrogenic causes of dyspeptic symptoms and to recognize and treat overlapping disease. Identification of $H$. pylori infection is appropriate, as prospective trials indicate that eradication therapy is curative in approximately 1 in 10 infected patients ${ }^{1}$. If the patient is not infected, then an empirical trial of acid suppression is justified to suppress symptoms related to an atypical presentation with GERD ${ }^{1}$. Individuals with overlap IBS may respond to spasmolytics and stool regulation.

Pharmacological treatments for FD that are more effective than placebo in randomized controlled trials and are available in the market are limited ${ }^{1,24}$. These include acid suppression (PPIs), H2 receptor antagonists (H2RAs), prokinetics, herbal preparations, and antidepressants ${ }^{1,24}$. Dietary interventions and medications that modulate digestive function may be more likely to be effective in PDS patients in whom abnormal gastric function is present ${ }^{1}$. Conversely, pain modulators and, if appropriate, antidepressants may be most appropriate in EPS ${ }^{1}$. This hypothesis is (indirectly) supported by the observation that the presence of normal gastric emptying on scintigraphy in patients with FD is associated with a good response to low-dose antidepressant medications that target visceral hypersensitivity (see below).

\section{Acid and reflux suppression}

A just-published Cochrane systematic review has concluded that PPIs are effective for the treatment of FD, independent of the dose and duration of treatment compared with placebo. PPIs may be slightly more effective than H2RAs for the treatment of FD, even if the evidence is scarce ${ }^{25}$. A recent randomized, placebocontrolled trial with an alginate-antacid preparation (Gaviscon) that controls both acid and non-acid reflux has also shown a significant benefit not only in typical reflux but also in dyspeptic (epigastric pain) symptoms ${ }^{26,27}$. It is uncertain what proportion of patients who respond to acid and reflux suppression have an atypical presentation of GERD.

\section{Prokinetics}

Historical studies with cisapride, a mixed 5-HT4 agonist and 5-HT3 antagonist with procholinergic effects, indicate that selected prokinetics can be more effective than placebo in treating $\mathrm{FD}^{24}$. Unfortunately, this medication is now restricted in most countries because of increased risk of tachyarrhythmia in patients with heart disease ${ }^{24}$. Only limited data are present for the dopamine- 2 antagonists domperidone and metoclopramide although they are prescribed extensively ${ }^{24}$. However, owing to cardiac and neurological side effects, the use of these medications for long-term treatment is not recommended. One phase IIb randomized, placebo-controlled study reported that itopride, a dopamine D2 antagonist and acetylcholinesterase inhibitor, is effective in FD, in particular for the management of pain and fullness ${ }^{24}$. However, two subsequent phase III trials were negative ${ }^{24}$. Whether this was related to the selection of different patient populations in the original Japanese and the subsequent US trials remains uncertain. More recent data have demonstrated that acotiamide at a dose of $100 \mathrm{mg}$ three times daily was efficacious and safe in the treatment of PDS $^{28-30}$. The drug has been commercially available in Japan since 2013, and trials in Europe and the USA are in progress ${ }^{28}$. Interestingly, a higher percentage of patients with PDS have been reported to respond to the treatments with acotiamide. It may be that this is related to effects on gastric motility and gastric emptying documented in animal models $^{28}$. Data have also recently appeared about the possible effect of prucalopride, a 5-HT4 agonist licensed in Europe and Canada for the treatment of refractory constipation, in treating FD. This drug increases oesophageal and gastric motility in healthy subjects ${ }^{31}$, and recent data, still in abstract form, have also reported a benefit in treating symptoms of patients with FD and gastroparesis $^{32}$. Iberogast (STW5), a nine-herb combination, has been shown in studies to relax the gastric fundus, promote gastric emptying, and reduce visceral sensitivity through multiple putative mechanisms ${ }^{1}$. Some clinical data also support its use, and it is a popular over-the-counter remedy for FD in several European countries. However, a recent report of severe hepatotoxicity leading to liver transplantation potentially associated with the use of Iberogast suggests some caution in prescribing this medication ${ }^{33}$. Finally, rikkunshito, another herbal medicine, which is thought to accelerate gastric emptying, has been shown to improve symptoms 
of epigastric pain and postprandial fullness in patients with FD in a randomized clinical trial ${ }^{34}$.

\section{Centrally acting drugs}

A substantial body of work supports the use of low-dose antidepressants in the management of FD and other functional GI disorders and chronic pain syndromes ${ }^{35}$. Talley et al. ${ }^{36}$ recently conducted an important randomized controlled trial that compared the effects of two classes of antidepressant in FD: (i) the tricyclic amitriptyline $(50 \mathrm{mg})$ and (ii) the selective serotonin reuptake inhibitor (SSRI) escitalopram $(10 \mathrm{mg})$. A large number ( $n=292$ ) of patients with Rome II dysmotility-like (similar to PDS) or ulcer-like (similar to EPS) FD were studied. Solid gastric emptying was documented by gastric scintigraphy, and the maximally tolerated ingestion of liquid nutrient was documented to estimate gastric accommodation and sensation ${ }^{36}$. Significant treatment effects were observed over 12 weeks. Amitriptyline, but not escitalopram, appeared to benefit patients with FD, particularly those with ulcer-like FD (EPS-like) ${ }^{36}$. Interestingly, delayed gastric emptying was associated with a poor response to treatment, a finding that supports the hypothesis that clinical presentation and physiological studies can help direct therapy ${ }^{36}$. These findings are consistent with the Nortriptyline for Idiopathic Gastroparesis (NORIG) study, which randomly assigned 130 patients with idiopathic gastroparesis to nortriptyline (a tricyclic antidepressant) or placebo for 15 weeks (91\% of patients met diagnostic criteria for PDS) ${ }^{37}$. In this study, active treatment was not superior to placebo in treating patients; however, the majority $(86 \%)$ had gastroparesis on scintigraphy ${ }^{37}$. Importantly, the trial by Talley et al. found that, although adverse events were commonly reported, there was no difference in side effects among the placebo, amitriptyline, and escitalopram, except in neurological symptoms with the $\mathrm{SSRI}^{36}$. These findings support the use of amitriptyline in FD patients without delayed gastric emptying. A course of therapy without documenting gastric emptying can be justified, as these medications are generally well tolerated at low doses.

A just-published meta-analysis concluded that certain neuroleptics, like levosulpiride, have prokinetic actions and are more effective than placebo in patients with FD in secondary or tertiary care $^{35}$. However, it remains uncertain whether other psychotropic drugs, including 5-HT1A receptor agonists, tetracyclic antidepressants, or serotonin-norepinephrine reuptake inhibitors (SNRIs), are effective treatments in $\mathrm{FD}^{35}$. In the case of 5-HT1A agonists, although there have been three trials, each used a different drug (sumatriptan, buspirone, and tandospirone), and the results were conflicting ${ }^{35}$. These medications are of particular interest because, in addition to their anxiolytic and antidepressant effects, both relax the gastric fundus and reduce gastric sensitivity (key pathological mechanisms in PDS). Trials reported reduced symptoms of postprandial fullness, early satiation, and upper abdominal bloating in randomized, placebo-controlled trials ${ }^{35}$. Unfortunately, although these medications are helpful in some individuals, sedative side effects limit their use in others. In the case of tetracyclic antidepressants and SNRIs, there has been only one trial of each of these drug classes (mirtazapine and venlafaxine) ${ }^{35}$.

\section{Psychological and other interventions}

Controlled trials suggest clinical benefit of psychological interventions from several, small randomized controlled studies ${ }^{38}$; however, the quality of evidence is still suboptimal. A recent systematic review concluded that acupuncture therapy achieves a statistically significant effect for FD in comparison with sham acupuncture and is superior to medication (prokinetic agents) in improving the symptoms and quality of life of patients with $\mathrm{FD}^{39}$. Nonetheless, despite stringent methodological analyses, there is still need for additional randomized controlled studies of higher quality $^{39}$.

\section{Is this information from the literature of any relevance for an evidence-based approach in our clinical practice?}

The authors of the present review work as clinical gastroenterologists with a specialist research interest in functional GI disorders and with experience in different European countries. They consider that the recent literature provides information that can inform and hopefully improve clinical practice. Table 2 and Figure 1, respectively, report the pharmacological options and the practical management algorithm in FD.

Whenever we consider the primary, secondary, or tertiary setting, it is of key importance to recognize the typical presentation of patients with FD. The Rome criteria are not primarily intended for use in clinical practice; however, it can be helpful to use symptom-based criteria to establish a "positive" diagnosis of this condition. This aids communication with the patient. At the same time, the criteria can help to differentiate FD from other conditions (for example, GERD alone, IBS alone, or chronic nausea and vomiting disorders). If alarm symptoms are present, then these should be investigated (even if there is a high suspicion of functional disease). If they are absent, then endoscopy is not mandatory at the initial presentation and non-invasive investigation is recommended to test for the presence of $H$. pylori and, if present, to eradicate it, regardless of the presence of different subgroups of patients with FD. Resolution of symptoms after eradication should be reassessed in a few months. In patients with a negative test for $H$. pylori or without resolution of symptoms after eradication, the symptoms of FD should be carefully evaluated to identify those with EPS, PDS, and overlap, which according to the recent publication should be considered $\mathrm{PDS}^{3}$.

EPS should be treated with acid suppressants. If PPI therapy is not effective, then some patients may benefit more from H2RAs ${ }^{24}$. An alternative (or supplementary) therapy is the addition of an alginate preparation, recently re-evaluated and found to be effective in the treatment of GERD ${ }^{26}$.

In patients with EPS, if a trial of acid and reflux suppression fails, then tricyclic antidepressants, such as amitriptyline, should be considered. In clinical practice, we start with slow increasing of the dose (normally amitriptyline $25 \mathrm{mg}$ one quarter daily for 1 week, then one half daily for another week, and finally one daily until the next consultation in about 2 months), informing the patient 
Table 2. Pharmacological treatment options for functional dyspepsia.

Acid suppression
Proton pump inhibitors (standard dose should be enough)
H2 receptor antagonists (less effective acid suppression than proton pump inhibitors; however, anti-histamine effects may be
beneficial in some patients with functional dyspepsia)
Prokinetic
Metoclopramide (limited evidence and not recommended for long-term treatment because of neurological side effects)
Domperidone (limited evidence and not recommended for long-term treatment because of potential cardiac arrhythmias)
Prucalopride (evidence based on one study published as abstract)
Acotiamide (evidence based on two phase III studies, currently available only in Japan)
Centrally acting drugs
Tricyclic antidepressants (for example, low-dose amitriptyline 25 mg daily, thought to reduce visceral hypersensitivity and
reduce functional pain)
Selective serotonin reuptake inhibitors (for example, paroxetine, primarily targeting co-existing anxiety and depression)
Neuroleptics (for example, levosulpiride also has prokinetic effects)
5-HT1 agonists (that is, buspirone, tandospirone anxiolytics that may also improve early satiety and postprandial distress)
Noradrenergic and specific serotonergic antidepressants (for example, mirtazapine has anxiolytic effects and may also relax
the gastric fundus, reduce early satiety, and improve appetite)
Herbal preparations
lberogast (no prescription required, may have prokinetic effects on gastric emptying with improvement in reflux and dyspeptic
symptoms)
Rikkunshito (may have prokinetic effects and improve dyspeptic symptoms)

about possible delayed benefit and early minor side effects (that is, dry mouth). We find this approach useful to minimize side effects and improve compliance. Moreover, a follow-up consultation at about 2 months reinforces the patient's motivation to continue the treatment.

In contrast, in patients with PDS, prokinetic therapy may improve symptoms. However, as summarized above, the market does not offer much choice. Taken on an as-required basis, domperidone or metoclopramide is a reasonable first choice for this patient group; however, long-term treatment is no longer recommended. The authors of the present review have obtained good clinical responses applying prucalopride in some patients with FD, as recently suggested by the literature. Starting with half the licenced dose for constipation (prucalopride $1 \mathrm{mg}$ daily) and building up to $2 \mathrm{mg}$ daily if tolerated is a useful addition, in particular in FD patients with overlapping constipation. In PDS patients who fail to respond, treatment with an antidepressant is the next step; however, it may be reasonable to check gastric emptying prior to starting treatment because the treatment response appears to be poor if delayed gastric emptying is present ${ }^{36}$. In severe cases, especially those with weight loss, mirtazapine can be a good choice since it also relaxes the stomach and promotes weight gain ${ }^{40}$. Given the frequent association with anxiety, if this is considered a likely driver of symptoms, then treatment with SSRIs is reasonable, even though no data support this approach in FD patients per se.
Certainly, anxiety and depression have been shown to impact on gastric motor and sensory function ${ }^{41}$.

In patients who do not respond to empirical treatment, further functional evaluations are normally advocated to select appropriate management ${ }^{1}$. However, many of these investigations are available in highly specialized referral centres or used primarily for research purposes or both ${ }^{42}$. The electronic barostat is considered the gold standard to assess gastric accommodation and visceral sensitivity, but the technique is invasive and is mainly used for research, and recent studies have suggested that the barostat bag could influence the gastric motor response ${ }^{42}$. New, less invasive techniques are in evaluation to replace the barostat. The nutrient drink test has been proposed as an alternative. In this test, a defined nutrient meal is ingested over a period of time until dyspeptic symptoms develop or the patient reports feeling full ${ }^{42}$. Response to treatment can be measured by repeating the test ${ }^{42}$. More recently, intragastric pressure measurement during a nutrient meal change was proposed as a minimally invasive test of nutrient tolerance and accommodation in $\mathrm{FD}^{42}$. However, the test needs further validation ${ }^{42}$. Gastric scintigraphy is the reference test of gastric emptying and is clinically more widely accessible than tests of accommodation $^{43}$. Methodology has been extensively validated; however, unfortunately, standard test meals are not widely applied ${ }^{43}$. In most centres, only the gastric emptying of solids is evaluated ${ }^{43}$. If gastric emptying is delayed, then the diagnosis of "gastroparesis" is made; 
1. Recognize FD symptoms, characterize the patient as PDS or EPS (if no link to food intake), and identify possible co-existing functional disorders (i.e. GERD or IBS) and psychological disorders (e.g. anxiety disorder)

- Enquire about the possible presence of all the upper GI symptoms: early satiety, postprandial fullness, epigastric pain, epigastric burning (to be differentiated from heartburn), nausea, vomiting (to be differentiated from regurgitation and rumination), belching, and dysphagia for solids and liquids.

- Enquire about the bowel habit (constipation, diarrhea, both) and the possible relationship with abdominal pain (epigastric pain relieved by defecation suggests IBS and not FD). Overlap symptoms are common.

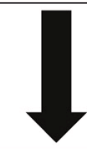

\section{Exclude alarm symptoms}

New-onset dyspeptic symptoms in patients $>45$ years old, dysphagia, repeated vomiting, unplanned weight loss ( $>5 \%$ body weight), anemia, family history for cancer, abnormal clinical examination. Plan endoscopy with biopsy to exclude Helicobacter pylori infection, celiac disease, and other inflammatory disorders.

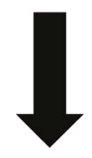

\section{Reassure and explain the pathophysiology of FD}

The patient should be reassured about the absence of cancer or organic disease and the complex interplay of factors possibly involved in the genesis of symptoms should be explained. In this context, it can help to ask about possible post-infectious onset of symptoms, as this facilitates the explanation of possible inflammatory damage of gut neurons controlling gut function.

\section{Suggest lifestyle and dietary modifications}

More frequent, smaller meals and avoiding meals with high-fat content probably works better in PDS than in EPS. LOW-FODMAP diet can be considered in patients overlapping with IBS.

\section{If a pharmacological treatment is needed, select the one that is more likely to work}

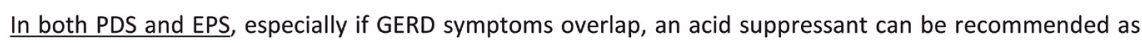
first-line treatment. Helicobacter pylori eradication therapy is indicated if the infection is present. 


\section{If empirical therapy does not provide adequate relief then further treatment depends on the phenotype}

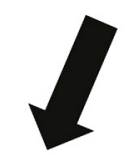

In EPS patients, low-dose amitriptyline or another TCA is indicated. In this case, explain to the patient that the treatment targets visceral hypersensitivity and so reduces pain sensation. Increase the dose slowly, give the patient the possibility to contact you in case of need, and arrange a follow-up visit in 2 months (explaining the drug can take time to start working properly)
In PDS patients and those with slow

gastric emptying, a prokinetic is

indicated (e.g. domperidone,

metoclopramide). Where available,

acotiamide may be first choice.

Prucalopride is an alternative, in

particular if constipation co-exists.

In PDS partially or not responding to

prokinetics, the addition of TCA or SSRI

can be considered. SSRI is appropriate if

anxiety and/or depression are a key

factor in presentation.

In both EPS and PDS refractory to all standard treatments

An intensified medical management involving psychological intervention and the addition of other

central acting agents (see Table 2) and/or acupuncture or hypnosis could be considered.

Figure 1. Practical management algorithm in functional dyspepsia. EPS, epigastric pain syndrome; FD, functional dyspepsia; FODMAP, fermentable oligosaccharides, disaccharides, monosaccharides, and polyols; GERD, gastro-oesophageal reflux disease; Gl, gastrointestinal; IBS, irritable bowel syndrome; PDS, postprandial distress syndrome; SSRI, selective serotonin reuptake inhibitor; TCA, tricyclic antidepressant. 
however, unless the delay is severe (for example, three times the upper limit of normal), there is only a weak association between this finding and patient symptoms or disease severity ${ }^{44}$. Moreover, it is not clear that the finding of gastroparesis predicts positive outcome for prokinetic medication ${ }^{44}$. Conversely, the diagnosis of gastric dumping has implications for dietary and pharmacological therapy ${ }^{44}$. It is interesting to note that patients with rapid gastric emptying (that is, dumping) can present with symptoms identical to those of gastroparesis and this may be the strongest reason to do the test ${ }^{44}$.

However, the reality is that after performing tests, at this time, not so many specific pharmacological therapies are available to correct abnormal physiology ${ }^{1}$. Nevertheless, there is evidence that a clear explanation for symptoms improves patient acceptance of disease and reduces out-patient attendance ${ }^{45}$. Otherwise, an intensified medical management involving psychological intervention could be applied, as this has been reported to give superior long-term outcomes ${ }^{46}$.

At present, the information obtained from gastric emptying studies is limited. For example, gastric scintigraphy studies often provide only a single measurement of gastric emptying of a solid meal. As already suggested ${ }^{43}$, it is unlikely that this captures the complexity of GI function (Figure 2). In particular, a single summary outcome measurement, normalized after ingestion of a meal, misses the "early gastric emptying" that occurs even during meal ingestion ${ }^{47}$. Moreover, the current way of performing the gastric emptying test does not incorporate the report of sensations experienced during meal ingestion ${ }^{47}$. A new development in this field is the combination of a nutrient drink test with gastric scintigraphy to obtain a comprehensive assessment of gastric motor and sensory function ${ }^{47}$. Assessment of the scintigraphic images after ingestion of the relatively large $(400 \mathrm{~mL})$ "Nottingham Test Meal" provides an evaluation of gastric accommodation and sensitivity in addition to gastric emptying ${ }^{47}$. The test uses standard technology, and normal values of this test have been published $^{48}$. Ongoing studies will disclose whether this test can predict the response to pharmacological treatments in clinical practice.

\section{Conclusions}

The literature of these last five years concerning FD has provided some relevant information for clinical practice. It has indeed confirmed the importance of correctly recognizing the different symptoms affecting the patient in order to identify PDS or EPS. This classification indeed seems to correspond to different pathophysiological mechanisms and treatments.

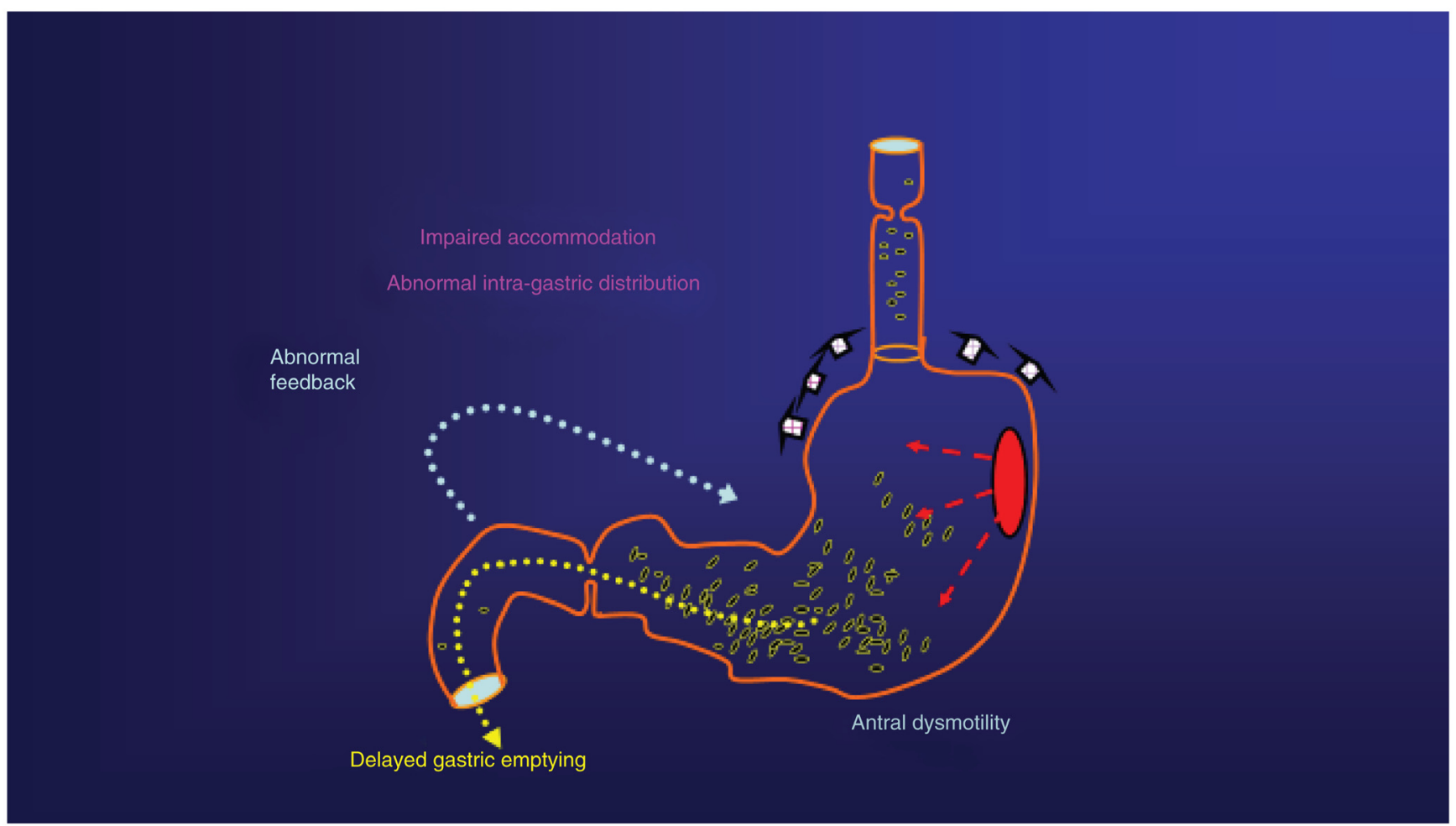

Figure 2. Abnormal gastric motility and function could be implicated in the pathophysiology of symptoms in functional dyspepsia, especially in patients with postprandial distress syndrome. Heightened visceral sensitivity has an important role in epigastric pain syndrome but is also present in many individuals with postprandial distress. In clinical practice, with the exception of detection of abnormal gastric emptying by scintigraphy, it is currently not possible to identify the specific causes of disease. 
However, it also reveals that we urgently need new tests to better study the GI function of these patients in order to develop effective treatments and better understand the pathophysiological mechanisms to target.

\section{Abbreviations}

CHS, cannabinoid hyperemesis syndrome; CNVS, chronic nausea and vomiting syndrome; CVS, cyclic vomiting syndrome; EPS, epigastric pain syndrome; ERD, erosive reflux disease; FD, functional dyspepsia; FH, functional heartburn; GERD, gastrooesophageal reflux disease; GI, gastrointestinal; IBS, irritable bowel syndrome; NERD, non-erosive reflux disease; PDS, postprandial distress syndrome; PPI, proton pump inhibitor; SNRI, serotonin-norepinephrine reuptake inhibitor; SSRI, selective serotonin receptor inhibitor.

Competing interests

The author declares that he has no competing interests.

Grant information

The author(s) declared that no grants were involved in supporting this work.
1. F Stanghellini V, Chan FK, Hasler WL, et al.: Gastroduodenal Disorders. Gastroenterology. 2016; 150(6): 1380-92.

PubMed Abstract | Publisher Full Text | F1000 Recommendation

2. Tack J, Talley NJ, Camilleri M, et al.: Functional gastroduodenal disorders. Gastroenterology. 2006; 130(5): 1466-79. PubMed Abstract | Publisher Full Text

3. F Carbone F, Holvoet $L$, Tack J: Rome III functional dyspepsia subdivision in PDS and EPS: recognizing postprandial symptoms reduces overlap. Neurogastroenterol Motil. 2015; 27(8): 1069-74. PubMed Abstract | Publisher Full Text | F1000 Recommendation

4. Tack J, Talley NJ: Functional dyspepsia--symptoms, definitions and validity of the Rome III criteria. Nat Rev Gastroenterol Hepatol. 2013; 10(3): 134-41. PubMed Abstract | Publisher Full Text

5. Vanuytsel T, van Wanrooy S, Vanheel $\mathrm{H}$, et al.: Psychological stress and corticotropin-releasing hormone increase intestinal permeability in humans by a mast cell-dependent mechanism. Gut. 2014; 63(8): 1293-9. PubMed Abstract | Publisher Full Text

6. Shindo T, Futagami S, Hiratsuka T, et al:: Comparison of gastric emptying and plasma ghrelin levels in patients with functional dyspepsia and non-erosive reflux disease. Digestion. 2009; 79(2): 65-72.

PubMed Abstract | Publisher Full Text

7. Bisschops R, Karamanolis G, Arts J, et al:: Relationship between symptoms and ingestion of a meal in functional dyspepsia. Gut. 2008; 57(11): 1495-503. PubMed Abstract | Publisher Full Text

8. Walker MM, Salehian SS, Murray CE, et al:: Implications of eosinophilia in the normal duodenal biopsy - an association with allergy and functional dyspepsia. Aliment Pharmacol Ther. 2010; 31(11): 1229-36. PubMed Abstract | Publisher Full Text

9. $\quad \mathrm{F}$ Aro P, Talley NJ, Ronkainen J, et al:: Anxiety is associated with uninvestigated and functional dyspepsia (Rome III criteria) in a Swedish population-based study. Gastroenterology. 2009; 137(1): 94-100. PubMed Abstract | Publisher Full Text |F1000 Recommendation

10. Wang $\mathrm{A}$, Liao $\mathrm{X}$, Xiong $\mathrm{L}$, et al:: The clinical overlap between functional dyspepsia and irritable bowel syndrome based on Rome III criteria. BMC Gastroenterol. 2008; 8: 43 .

PubMed Abstract | Publisher Full Text | Free Full Text

11. Kim SE, Chang L: Overlap between functional GI disorders and other functional syndromes: what are the underlying mechanisms? Neurogastroenterol Motil. 2012; 24(10): 895-913.

PubMed Abstract | Publisher Full Text | Free Full Text

12. Aziz Q, Fass R, Gyawali CP, et al.: Functional Esophageal Disorders Gastroenterology. 2016; 105(6): 1368-1379. pii: S0016-5085(16)00178-5. PubMed Abstract | Publisher Full Text

13. Quigley EM, Lacy BE: Overlap of functional dyspepsia and GERD--diagnostic and treatment implications. Nat Rev Gastroenterol Hepatol. 2013; 10(3): 175-86. PubMed Abstract | Publisher Full Text

14. Piessevaux H, De Winter B, Louis E, et al:: Dyspeptic symptoms in the general population: a factor and cluster analysis of symptom groupings.
Neurogastroenterol Motil. 2009; 21(4): 378-88.

PubMed Abstract | Publisher Full Text

15. Choung RS, Locke GR 3rd, Schleck CD, et al:: Overlap of dyspepsia and gastroesophageal reflux in the general population: one disease or distinct entities? Neurogastroenterol Motil. 2012; 24(3): 229-34, e106.

PubMed Abstract | Publisher Full Text | Free Full Text

16. $\mathrm{F}$ Savarino $\mathrm{E}$, Pohl $\mathrm{D}$, Zentilin $\mathrm{P}$, et al.: Functional heartburn has more in common with functional dyspepsia than with non-erosive reflux disease. Gut. 2009; 58(9): 1185-91.

PubMed Abstract | Publisher Full Text | F1000 Recommendation

17. Xiao YL, Peng S, Tao J, et al:: Prevalence and symptom pattern of pathologic esophageal acid reflux in patients with functional dyspepsia based on the Rome III criteria. Am J Gastroenterol. 2010; 105(12): 2626-31. PubMed Abstract | Publisher Full Text

18. Futagami S, Shindo T, Kawagoe T, et al:: Migration of eosinophils and CCR2/CD68-double positive cells into the duodenal mucosa of patients with postinfectious functional dyspepsia. Am J Gastroenterol. 2010; 105(8): 1835-42. PubMed Abstract | Publisher Full Text

19. F Vanheel H, Vicario M, Vanuytsel T, et al:: Impaired duodenal mucosal integrity and low-grade inflammation in functional dyspepsia. Gut. 2014; 63(2): 262-71. PubMed Abstract | Publisher Full Text | F1000 Recommendation

20. Mearin F, Lacy BE, Chang L, et al.: Bowel Disorders. Gastroenterology. 2016; 150(6): 1393-1407-e5. pii: S0016-5085(16)00222-5. PubMed Abstract | Publisher Full Text

21. Futagami S, Yamawaki H, Shimpuku M, et al.: Impact of coexisting irritable bowel syndrome and non-erosive reflux disease on postprandial abdominal fullness and sleep disorders in functional dyspepsia. J Nippon Med Sch. 2013; 80(5): 362-70.

PubMed Abstract | Publisher Full Text

22. Piacentino D, Cantarini R, Alfonsi M, et al:: Psychopathological features of irritable bowel syndrome patients with and without functional dyspepsia: a cross sectional study. BMC Gastroenterol. 2011; 11: 94 PubMed Abstract | Publisher Full Text | Free Full Text

23. Ford AC, Marwaha A, Lim A, et al:: Systematic review and meta-analysis of the prevalence of irritable bowel syndrome in individuals with dyspepsia. Clin Gastroenterol Hepatol. 2010; 8(5): 401-9. PubMed Abstract | Publisher Full Text

24. F Talley NJ: Functional Dyspepsia: Advances in Diagnosis and Therapy. Gut Liver. 2017: 11(3): 349-57.

PubMed Abstract | Publisher Full Text | Free Full Text | F1000 Recommendation

25. F Pinto-Sanchez MI, Yuan Y, Bercik $\mathrm{P}$, et al.: Proton pump inhibitors for functional dyspepsia. Cochrane Database Syst Rev. 2017; 3: CD011194. PubMed Abstract | Publisher Full Text | F1000 Recommendation

26. F Coyle C, Crawford G, Wilkinson J, et al.: Randomised clinical trial: addition of alginate-antacid (Gaviscon Double Action) to proton pump inhibitor therapy in patients with breakthrough symptoms. Aliment Pharmacol Ther. 2017; 45(12): 1524-33.

PubMed Abstract | Publisher Full Text | F1000 Recommendation 
Thomas E, Wade A, Crawford G, et al:: Randomised clinical trial: relief of upper gastrointestinal symptoms by an acid pocket-targeting alginate-antacid (Gaviscon Double Action) - a double-blind, placebo-controlled, pilot study in gastrooesophageal reflux disease. Aliment Pharmacol Ther. 2014; 39(6): 595-602. PubMed Abstract | Publisher Full Text

28. F Matsushita M, Masaoka $\mathrm{T}$, Suzuki H: Emerging treatments in neurogastroenterology: Acotiamade, a novel treatment option for functional dyspepsia. Neurogastroenterol Motil. 2016; 28(5): 631-8.

PubMed Abstract | Publisher Full Text | F1000 Recommendation

29. Nakamura K, Tomita T, Oshima T, et al.: A double-blind placebo controlled study of acotiamide hydrochloride for efficacy on gastrointestinal motility of patients with functional dyspepsia. J Gastroenterol. 2017; 52(5): 602-10. PubMed Abstract | Publisher Full Text

30. Matsueda $\mathrm{K}$, Hongo $\mathrm{M}$, Tack J, et al.: A placebo-controlled trial of acotiamide for meal-related symptoms of functional dyspepsia. Gut. 2012; 61(6): 821-8. PubMed Abstract | Publisher Full Text | Free Full Text

31. Kessing BF, Smout AJ, Bennink RJ, et al:: Prucalopride decreases esophageal acid exposure and accelerates gastric emptying in healthy subjects. Neurogastroenterol Motil. 2014; 26(8): 1079-86. PubMed Abstract | Publisher Full Text

32. Carbone F, Rotondo A, Andrews CN, et al.: 1077 A Controlled Cross-Over Trial Shows Benefit of Prucalopride for Symptom Control and Gastric Emptying Enhancement in Idiopathic Gastroparesis. Gastroenterology. 2016; 150(4, supplement 1): S213-S214. Publisher Full Text

33. Sáez-González E, Conde I, Díaz-Jaime FC, et al:: Iberogast-Induced Severe Hepatotoxicity Leading to Liver Transplantation. Am J Gastroenterol. 2016; 111(9): 1364-5.

PubMed Abstract | Publisher Full Text

34. F Suzuki H, Matsuzaki J, Fukushima Y, et al:: Randomized clinical trial: rikkunshito in the treatment of functional dyspepsia--a multicenter, doubleblind, randomized, placebo-controlled study. Neurogastroenterol Motil. 2014 26(7): 950-61.

PubMed Abstract | Publisher Full Text | F1000 Recommendation

35. F Ford AC, Luthra $\mathrm{P}, \mathrm{Tack} \mathrm{J}$, et al.: Efficacy of psychotropic drugs in functional dyspepsia: systematic review and meta-analysis. Gut. 2017; 66(3): 411-20. PubMed Abstract | Publisher Full Text | F1000 Recommendation

36. F Talley NJ, Locke GR, Saito YA, et al:: Effect of Amitriptyline and Escitalopram on Functional Dyspepsia: A Multicenter, Randomized Controlled Study. Gastroenterology. 2015; 149(2): 340-9.e2.

PubMed Abstract | Publisher Full Text | Free Full Text | F1000 Recommendation

37. F Parkman HP, van Natta ML, Abell TL, et al.: Effect of nortriptyline on ymptoms of idiopathic gastroparesis: the NORIG randomized clinical trial. JAMA. 2013; 310(24): 2640-9.

PubMed Abstract | Publisher Full Text | Free Full Text | F1000 Recommendation
38. Soo S, Moayyedi P, Deeks J, et al.: Psychological interventions for non-ulcer dyspepsia. Cochrane Database Syst Rev. 2005; 2: CD002301.

PubMed Abstract | Publisher Full Text

39. F Pang B, Jiang T, Du YH, et al:: Acupuncture for Functional Dyspepsia: What Strength Does It Have? A Systematic Review and Meta-Analysis of Randomized Controlled Trials. Evid Based Complement Alternat Med. 2016; 2016 3862916.

PubMed Abstract | Publisher Full Text | Free Full Text | F1000 Recommendation

40. F Tack J, Ly HG, Carbone F, et al.: Efficacy of Mirtazapine in Patients With Functional Dyspepsia and Weight Loss. Clin Gastroenterol Hepatol. 2016; 14(3): 385-392.e4.

PubMed Abstract | Publisher Full Text | F1000 Recommendation

41. F Ly HG, Weltens N, Tack J, et al:: Acute Anxiety and Anxiety Disorders Are Associated With Impaired Gastric Accommodation in Patients With Functional Dyspepsia. Clin Gastroenterol Hepatol. 2015; 13(9): 1584-91.e3.

PubMed Abstract | Publisher Full Text | F1000 Recommendation

42. F Vakil NB, Howden CW, Moayyedi P, et al:: White Paper AGA: Functional Dyspepsia. Clin Gastroenterol Hepatol. 2017; 15(8): 1191-4.

PubMed Abstract | Publisher Full Text | F1000 Recommendation

43. Maurer $\mathrm{AH}$ : Advancing gastric emptying studies: standardization and new parameters to assess gastric motility and function. Semin Nucl Med. 2012; 42(2): 101-12.

PubMed Abstract | Publisher Full Text

44. Stanghellini V, Tack J: Gastroparesis: separate entity or just a part of dyspepsia? Gut. 2014; 63(12): 1972-8

PubMed Abstract | Publisher Full Text

45. Ward BW, Wu WC, Richter JE, et al.: Long-term follow-up of symptomatic status of patients with noncardiac chest pain: is diagnosis of esophageal etiology helpful? Am J Gastroenterol. 1987; 82(3): 215-8. PubMed Abstract

46. Haag S, Senf W, Tagay S, et al.: Is there a benefit from intensified medical and psychological interventions in patients with functional dyspepsia not responding to conventional therapy? Aliment Pharmacol Ther. 2007; 25(8): 973-86.

PubMed Abstract | Publisher Full Text

47. Parker HL, Tucker E, Hoad CL, et al:: Development and validation of a large, modular test meal with liquid and solid components for assessment of gastric motor and sensory function by non-invasive imaging. Neurogastroenterol Motil. 2016; 28(4): 554-68.

PubMed Abstract | Publisher Full Text

48. Parker HL, Tucker E, Blackshaw E, et al.: Clinical assessment of gastric emptying and sensory function utilizing gamma scintigraphy: Establishment of reference intervals for the liquid and solid components of the Nottingham test meal in healthy subjects. Neurogastroenterol Motil. 2017.

PubMed Abstract | Publisher Full Text 


\section{Open Peer Review}

\section{Current Peer Review Status:}

\section{Editorial Note on the Review Process}

Faculty Reviews are review articles written by the prestigious Members of Faculty Opinions. The articles are commissioned and peer reviewed before publication to ensure that the final, published version is comprehensive and accessible. The reviewers who approved the final version are listed with their names and affiliations.

\section{The reviewers who approved this article are:}

\section{Version 1}

\section{Hiroto Miwa}

Division of Gastroenterology, Department of Internal Medicine, Hyogo College of Medicine, Nishinomiya, Hyogo, Japan

Competing Interests: No competing interests were disclosed.

\section{Fermin Mearin}

Digestive System Department, Centro Médico Teknon, Barcelona, Spain

Competing Interests: No competing interests were disclosed.

The benefits of publishing with F1000Research:

- Your article is published within days, with no editorial bias

- You can publish traditional articles, null/negative results, case reports, data notes and more

- The peer review process is transparent and collaborative

- Your article is indexed in PubMed after passing peer review

- Dedicated customer support at every stage

For pre-submission enquiries, contact research@f1000.com 